\section{The need to develop an evidence base for genetic counselling in Europe}

\author{
European Journal of Human Genetics (2016) 24, 504-505; \\ doi:10.1038/ejhg.2015.134; published online 15 July 2015
}

We write regarding the need for genetic counselling research across Europe. At risk relatives of the 30 million Europeans affected by genetic conditions may be neither recognised nor managed appropriately by health professionals. ${ }^{1}$ This contravenes the EU's aim to create safe, efficient, patient-centred and sustainable health-care systems. ${ }^{2}$ For service development, a firm evidence base is needed. Areas where evidence is lacking include service provision, service quality and genetic counselling process.

\section{SERVICE PROVISION}

Genetic counselling is an emerging profession in Europe. ${ }^{3}$ In most European countries where genetic counsellors are employed, they work in multi-disciplinary teams with medically qualified clinical geneticists, who can diagnose genetic conditions. Genetic counsellors' expertise focuses on communication and facilitating patient decision-making and adaptation to a genetic diagnosis in the family. Specialist genetic counselling service provision to accompany genetic testing is patchy, with other health-care professionals increasingly using genomic data in patient management. In many countries genetic counselling is provided by individuals without the required competences. ${ }^{4}$ In Europe, Masters level genetic counsellor training programmes are only offered in the United Kingdom, Portugal, Romania, France and Spain (https://www.eshg.org/408.0.html). Access to genetic counsellors for families affected by genetic conditions is not equal across Europe. Cordier et al. ${ }^{3}$ mapped use of genetic counsellors/nurses in 18 European countries. While these practitioners had a significant role in Netherlands, France, United Kingdom, Norway and Sweden, other countries (for example: Turkey, Hungary, Germany) had no genetic counsellors/nurses working at all. Where genetic counsellors were employed, their role differed between countries. However, this study focused only on these professions. A broader view of genetic services provided by all professionals involved is needed.

Owing to the range of cultural, healthcare and educational contexts across Europe, it seems unlikely that one service model can be applied everywhere. Research is needed to map service provision across Europe, to develop appropriate models and to design and test interventions applicable where those models are used.

\section{SERVICE QUALITY}

There is little evidence regarding genetic service quality across Europe. Clarke et al. developed a quality checklist for internal audit of genetic services. ${ }^{5}$ This practical tool addresses issues of service provision, for example: staffing, training, waiting times and clinic facilities. While these aspects are important, they do not reflect patient experiences and outcomes. More health services research is needed to develop a robust tradition of evidence-based practice to maximize patient-reported experiences and outcomes.
Evaluation of clinical genetics has been problematic because the patient benefits have been difficult to specify and measure. Patient mortality and health status are unlikely to be improved directly for most patients, at least not in the short-term. Patient-reported outcomes (PROs) will become more important because patient-reported outcome measures (PROMs) are increasingly used to contribute to health-care service management and funding worldwide.

Research has identified patient benefits from genetics services, summarized using the term 'empowerment' (cognitive, decisional and behavioural control, emotional regulation and hope), which was operationalized in a well-validated 24-item PROM: the Genetic Counselling Outcome Scale (GCOS-24). ${ }^{6}$ GCOS-24 was used in service evaluation exercises in six of the 25 UK regional clinical genetics centres in 2011-2013, and in Canada to evaluate psychiatric genetic counselling in 2013. ${ }^{7}$ Findings demonstrated that genetic counselling can deliver significant measurable patient benefits. However, to enable services in other EU countries to be evaluated in this way, this and/or similar tools need appropriate translation, crosscultural adaptation and psychometric validation for use in languages other than English. ${ }^{8}$ Current procedures for quality assessment of genetic counselling practice were investigated using a Delphi study of European experts, who suggested use of patient feedback, clinical case discussion and clinical supervision to ensure service quality. ${ }^{9}$

\section{GENETIC COUNSELLING PROCESS}

Research has consistently demonstrated that genetic counselling improves patient knowledge, risk perception and autonomy in decision-making, decreases stigma experienced and generates high patient satisfaction. ${ }^{6}$ Nevertheless, several challenges remain across Europe: (i) professionals from many backgrounds (eg, nurses, psychologists and scientists) are trained in genetic counselling but their counselling skills remain uneven irrespective of training; (ii) counselling interventions are only exceptionally evidence-based; genetic counsellors have heterogeneous views and approaches to psychological interventions; ${ }^{10}$ (iii) professional guidelines regarding evidence-based genetic counselling are still emerging while evidencebased psychological counselling/psychotherapy guidelines are already available (see http://www.nice.org.uk; http://www.div12.org/Psychological Treatments/index.html; Cochrane Reviews http://www.cochrane.org). These guidelines could provide a starting point for calibrating evidence-based genetic counselling practice.

Genetic counselling is rooted in many different traditions, both theoretically based approaches (psychodynamic therapy, family systems theory) and more evidence-based interventions (eg, cognitivebehaviour therapy $(\mathrm{CBT})$ ). However, conceptual frameworks that bring together the range of models and perspectives are lacking, and the breadth of research is difficult for clinicians to translate into effective practice. Future research, practice and training should take account of the efficacy of genetic counselling interventions, and evidence for the underlying theory of change.

Common overarching integrative frameworks are needed to inform evidence-based genetic counselling and to overcome the current fragmentation between theory-based and evidence-based approaches. Focusing on empirically supported principles of change will enable specification and evaluation of interventions for delivery of patient benefits.

Robust health services and educational research are needed in genetic counselling across Europe to support service development to 
meet the needs of affected families. A critical mass for this type of research will enable development of genetic counselling services to meet the needs of European families affected by genetic conditions for economic and social benefit.

\section{CONFLICT OF INTEREST}

The authors declare no conflict of interest.

Marion McAllister ${ }^{1}$, Ramona Moldovan², Milena Paneque ${ }^{3}$ and Heather Skirton ${ }^{4}$

${ }^{1}$ School of Medicine, Cardiff University, Cardiff, UK; ${ }^{2}$ Department of Psychology, Babes-Bolyai University, Cluj-Napoca, Romania; ${ }^{3}$ Institute for Molecular and Cell Biology (IBMC), Porto, Portugal; ${ }^{4}$ School of Nursing and Midwifery, Plymouth University,

Plymouth, UK

E-mail: McAllisterMF@cardiff.ac.uk

1 Baars MJH, Henneman L, ten Kate LP: Deficiency of knowledge of genetics and genetic tests among general practitioners, gynecologists, and pediatricians: A global problem. Genet Med 2005; 7: 605-610.
2 European commission. Innovation Union, 2011. Available at http://ec.europa.eu/ research/innovation-union/index en.cfm (Accessed 24 April 2014).

3 Cordier C, Lambert D, Voelckel MA, Hosterey-Ugander U, Skirton H: A profile of the genetic counsellor and genetic nurse profession in European countries. J Commun Genet 2012; 3: 19-24.

4 Skirton H, Lewis C, Kent A, Coviello DA: Genetic education and the challenge of genomic medicine: development of core competences to support preparation of health professionals in Europe. Eur J Hum Genet 2010; 18: 972-977.

5 Clarke A, Evers-Kiebooms G, Faucett $A$ et al: Instrument for internal assessment of the quality of genetic counselling within a genetic counselling clinic, 2008. Available at http://www.eurogentest.org/professionals/db/news/499/index.xhtml (Accessed 18 July 2014).

6 McAllister M, Dearing A: Patient reported outcomes and patient empowerment in clinical genetics services. Clin Genet 2014, Online First doi:10.1111/cge.12520.

7 Inglis A, Koehn D, McGillivray B, Stewart SE, Austin J: Evaluating a unique, specialist psychiatric genetic counseling clinic: uptake and impact. Clin Genet 2015; 87 . 218-224.

8 Wild D, Grove A, Martin M, McElroy S, Verjee-Lorenz A, Erikson P: Principles of good practice for the translation and cultural adaptation process for patient-reported outcomes (PRO) measures: Report of the ISPOR Task Force for Translation and Cultural Adaptation. Value Health 2001; 8: 94-104.

9 Paneque M, Sequeiros J, Skirton H: Quality issues concerning genetic counselling for presymptomatic testing: a European Delphi study. Eur J Hum Genet 2015; doi:10.1038/ejhg.2015.23

10 Austin J, Semaka A, Hadjipavlou G: Conceptualizing genetic counseling as psychotherapy in the era of genomic medicine. J Genet Couns 2014; 23: 903-909. 